\title{
La nada germinal: Desplazamiento y transformación ritual en La Noche de Jaime Saenz
}

Victor Vimos

The Ohio State University

\begin{abstract}
In Jaime Saenz's poem La Noche, mystical, linguistic, and symbolic elements interact to alter our conception of reality. I carry out such a reading by focusing on ritual and the ways that it influences Saenz's poetic language. I show that this poem proposes to think about night as a cyclical territory in which time and space are decentered from their daily useage. This decentering reflects an identity crisis that emerges when we come face to face with the alterity within ourselves.
\end{abstract}

Keywords

Identity, Jaime Saenz, La Noche, poetry, ritual

\section{Resumen}

En el poema La Noche de Jaime Saenz se ve la interacción de elementos místicos, lingüísticos y simbólicos que alteran nuestra forma de concebir la realidad. Realizo su lectura enfocándome en el rito y cómo éste influye el lenguaje poético. Muestro que este poema propone pensar la noche como un 
territorio cíclico en el que el tiempo y el espacio se descentran de su uso cotidiano. Este descentramiento refleja la crisis de identidad que surge cuando enfrentamos la alteridad dentro de nosotros mismos.

\section{Palabras clave}

Identidad, Jaime Saenz, La Noche, poesía, ritual

En el poemario La Noche (1984), Jaime Saenz (1921-1986) explora el desplazamiento del individuo desde su funcionalidad social automatizada en lo cotidiano - la superficie y el día - hacia un estado desautomatizado de acción y atención -la profundidad y la noche. Este movimiento deviene en un modo singular de ocupar el tiempo y el espacio a través de la modificación de vínculos con la realidad. ${ }^{1}$ Se trata de un estar, en este caso, que implica contemplar la reconfiguración de las formas del yo y de la otredad.

En el presente artículo propongo la lectura de La Noche como un proceso ritual y recurro a tres conceptos para comprender mejor la exploración mística de Saenz y el retorno a la unidad original: ${ }^{2}$ el rito, asumido como un sistema de cambio y modulación a través de la crisis sensorial y simbólica que vive el individuo; la identidad, en tanto discurso modificable en el proceso ritual; y la corporalidad, asimilada por Saenz, en su diálogo y estudio de místicos como Miguel de Molinos, Santa Teresa y San Juan. Me interesa analizar cómo el poeta transforma su relación con la realidad mediante el descentramiento del núcleo

\footnotetext{
${ }^{1}$ Un segmento central de reflexión en este poemario está trazado sobre la desconfianza con la que Saenz observa la relación de la realidad con los sentidos, para él, automatizados a la producción material que en nombre del progreso sostiene la cotidianidad. De este modo, observa, el hombre habría perdido terreno en lo trascendental, en lo sagrado. La alternativa frente a ello estaría en distorsionar la relación sentidos-realidad y lograr que las sensaciones amplíen sus zonas de referencia generando versiones heterogéneas de la experiencia. Para ello es necesario atravesar disciplinadamente un proceso de iniciación y entrega al terreno de "la noche" que actuará como fuerza modificadora de lo sensorial, afectando radicalmente la función de acercamiento, exploración y diálogo con la realidad.

${ }^{2}$ En la obra de Jaime Saenz las nociones de unidad y totalidad son re-significaciones con las que el autor dialoga a propósito de su exploración mística. Blanca Wiethüchter (1975) observa que un elemento clave en la trayectoria poética de Saenz sería la idea de complementariedad hacia la unidad del cuerpo y el espíritu, actitud orientada al retorno a un estado de calma y quietud original. Desde esa perspectiva, el poeta está continuamente ampliando su relación con la idea de cuerpo y espíritu a favor del establecimiento de formas reconocibles y replicables de contacto con el todo unitario.
} 
simbólico del día por la fuerza generadora de cambio que trae la noche; cómo las nociones de tiempo y espacio son reconfiguradas, oponiendo al paradigma temporal-lineal la idea de ciclo temporal, que renueva la versión de espacio interior del individuo. $Y$ es que el proceso iniciático que yace en $L a$ Noche, al que el poeta se entrega de forma radical y disciplinada, pone en crisis el discurso identitario y la relación con la otredad; $y$, a partir del contacto entre el individuo y la sacralidad, abre un espacio para la borradura que da lugar al descubrimiento de otra realidad, a la enunciación de la voz.

\section{Tiempo y espacio: alteración inicial}

José Ángel Valente (1974) observó que el poeta, en su empeño por decir, construye una relación singular con el lenguaje, al que dispone como una red abarcadora que intenta contener el acto humano en el terreno de la significación. Sin embargo este empeño es evadido, pues desde fuera de la red, entre sus grietas, se filtran fragmentos de una experiencia individual que resisten al orden y decodificación del sentido, contaminando la referencialidad del acto humano y tensionando la red para devorar la intención de un lenguaje totalmente abarcador. Lo que queda son los fragmentos de un lenguaje poblado por experiencias que se resisten a ser dichas, a ser significadas y, por lo mismo, deterioran la versión racional-occidental de la realidad. El poeta entonces acecha desde diferentes ángulos esas resistencias.

Un mes antes de morir, Jaime Saenz se encerró y tapió con cartón todas las ventanas de su habitación. Ambas acciones, evitar al extremo la exposición a la luz y habitar un lugar creado en la oscuridad, pueden ser leídas como vías para tensionar la red del lenguaje cotidiano e ingresar a la experiencia mística. ${ }^{3}$ Predomina, en esta dirección, la voluntad hacia la cancelación radical de cualquier vínculo con el exterior y la distorsión del tiempo y el espacio.

La temporalidad que Saenz experimenta en estas condiciones difiere de la que se vive en el tiempo social - afuera - porque en lugar del avance lineal de las horas recrea la experiencia de la duración cíclica. El tiempo dentro de la

\footnotetext{
${ }^{3}$ Una de las marcas distintivas en la exploración poética de Saenz es la noción de estado que propone como alternativa de existencia. Estar en disposición para la observación del mundo es un punto fundamental en su relación con el lenguaje. Para alcanzarlo, para devenir en ese estar, Saenz confía en una serie de procesos de transformación personal que permiten, en la medida en que se tornan progresivamente más profundos, sostener ese estado el mayor tiempo posible. La escritura poética, sería, desde esta perspectiva, una materialización de la experiencia que el individuo vive ahí.
} 
habitación no transcurre como una sucesión de instantes; por el contrario, al renovarse constantemente, genera la apertura de un estar en el tiempo, un estado de atención de los sentidos frente al espacio interior. Del mismo modo la palabra cotidiana, comunicacional, es modificada hacia un acto distinto de su tarea de significación, es transformada en "una forma de contemplación" (Valente 14). Sostengo que contemplar desde la palabra es un modo de estar en la palabra: el individuo se aparta de su estado funcional en el que es necesario comunicar para sobrevivir y, en cambio, abre una temporalidad generadora de conciencia donde su efectividad no está medida por la precisión comunicativa tanto como por la duración que el individuo logre en ella. La duración de la atención que descubre la dinámica propia de cada palabra:

la noche encerrada en una caja que se vuelve noche aquella cómoda en el rincón del cuarto (La Noche 11)

El espacio también es alterado por esta relación. Opuesto a la noción de afuera, Saenz propone el interior como un lugar de sucesos reales, capaces o no de enunciar en la superficie, pero determinantes al momento de construir alternativas frente a sí mismo y la otredad. Es un espacio enrarecido que continuamente será afectado por el desplazamiento que el poeta haga en el lenguaje y que, a la vez, influirá en las experiencias que encarne. La dimensión interior del individuo ratificará al cuerpo como territorio primordial a ser afectado por la modificación sensorial. Las versiones de lo real, en este sentido, estarán ligadas a la espacialidad interior y serán repensadas y actualizadas hacia el exterior:

por obra de una fuerza que ha venido de quien sabe donde el espacio de mi sueño ha sido dividido por una pared (11)

A partir de estos cambios en el tiempo y espacio, el poeta internaliza, como práctica iniciática, el distanciamiento consigo mismo.

\section{Escisión del individuo}

El distanciamiento individual, de acuerdo a Blanca Wiethüchter, es una condición del ser escindido que "dividido tiene que ser negado por el nuevo ser verdadero: la identidad entre el poeta y lo otro, entre el yo y el tú" (1975, 
286). ${ }^{4}$ La ruptura con la superficie - el afuera - a través de la reconfiguración del tiempo y el espacio segmenta y cuestiona la versión racional de lo real: se modifica y modifica el lenguaje en el que se manifiesta. El poeta deja un rastro de su ingreso a la escisión; su palabra no es más un referente que representa a la realidad externa a través del uso simbólico de la superficie; su palabra ahora es referencia en sí misma. Relata la realidad que acontece en el tránsito de ese desprendimiento. Esta forma de lenguaje dispone nuevas coordenadas en la relación consigo mismo y con la otredad, pues lo que nombra está abierto a una manifestación real de la lengua en que las referencias y representaciones simbólicas son operaciones en continua producción y alteración. En este nivel, el yo del poeta es una interferencia en revelación constante.

Esta alteración de la identidad como camino de revelación a partir del distanciamiento consigo mismo coincide con el principio místico del deshacimiento al que Saenz atendió a través de la lectura detallada de San Juan de la Cruz, y quien, a su vez, vio en esta posibilidad una clave para "la destrucción de la identidad del sí mismo [...] del que no es otro con respecto a nadie" (Valente 14). Rasgo clave y constante de los versos que componen La Noche y donde se advierte la crisis de la mirada propia del individuo:

¿En qué consiste el otro lado de la noche?

El otro lado de la noche consiste en que la noche, simple y Llanamente,

se te entra por la espalda y se posesiona de tus ojos, para mirar con ellos lo que no puede mirar con los suyos.

Entonces ocurre una cosa muy rara:

en determinado momento, tú empiezas a mirar el otro lado de la noche,

y muy pronto llegas a comprender que éste se halla ya dentro de ti." (15-16)

\footnotetext{
${ }^{4}$ El texto "Borges y Yo" (1960) sirve como elemento de diálogo con esta reflexión de Wiethüchter. La cercanía que ella mira con la versión de Saenz es la línea temporal en que sostiene la existencia de una experiencia doble, que supera la limitación cotidiana, intrascendente, del ser humano. Sin embargo, la diferenciación radica en la noción saenciana de superación de esas limitaciones en un doble que no es ajeno sino que resulta del devenir del mismo individuo, un doble en el que se deviene por intermedio de una afectación en los sentidos y en la relación de estos con la realidad. El otro borgeano es, en Saenz, otro en revelación interior constante.
} 
La mirada del poeta cuestiona la centralidad del yo y, al hacerlo, abre dos procesos consecutivos: el primero, orientado hacia la desintegración del lugar de enunciación a partir de la desarticulación del discurso de la identidad; y, el segundo, la ocupación de ese espacio de desarticulación por la experiencia de tránsito y modificación ritual. La voz de quien se destruye a sí mismo sería en La Noche una voz en tránsito y renovación.

\section{El tránsito de la voz: ambigüedad, sacralidad y borradura}

Jaime Saenz esboza el tránsito de esa voz mediante las secciones tituladas "La Noche", "El Guardián", "Intermedio" y, otra vez, "La Noche". Entendidas como complementarias, estas etapas son estadios específicos que estructuralmente pueden ser leídos como un proceso ritual donde el poeta explora la modificación del yo identitario para rehacer los vínculos con la realidad mediante el encuentro con lo sagrado.

Se trata de un ritual que permite la reorganización de las fuerzas que provienen de afuera y la singularización de tiempo y espacio interior. Al respecto, Carlo Severi asegura que la ambigüedad que caracteriza a este territorio de reorganización se debe a que "[t]he field of ritual symbolism is thus described as the reorganization by analogy or contrast of notions presents in other areas of tradition, such as myths and proverbs" $(2006,584)$ [el campo del simbolismo ritual es descrito como la reorganización por analogía o contraste de nociones presentes en otras áreas de la tradición, como mitos y proverbios], y agrega que "ritual is considered as masked speech" (584) [el ritual se considera un discurso enmascarado. Traducción del autor], pues trabaja sobre una frontera permeable entre la voz enunciada y las múltiples direcciones que esta puede tomar. La oposición entre término y significado dan cuenta de esta movilización:

Luego la noche vendrá en tu ayuda

-y tan sólo ahora, a la luz de experiencias aterradoras recientemente vividas,

te serán reveladas muchas cosas simples, al par que difíciles. locura,

Pues si no hay riesgo, sino hay peligro, si no hay dolor y

no hay nada. (19) 
La sacralidad en La Noche se construye sobre esta ambigüedad porque la aceptación de lo sacro es un territorio de crisis. Mary Douglas invita a pensar una sacralidad distanciada del ascetismo católico en el que ha sido encapsulada postulando que "the sacred is at once 'sacred' and 'defiled'" $(2001,8)$ [lo sagrado es a la vez 'sagrado' y 'profano'. Traducción del autor] y, a partir de esta indeterminación, redefinir su contacto e interacción con el ser. Lo sagrado aparece entonces como una interferencia que tiende a establecer vías de afección mutua entre lo humano y lo divino.

La noche propicia para perderse y desaparecer, para renacer y morir, en oscuridades que te hablan y te señalan.

Por eso la luz de la noche es una luz aparte: muchas cosas, muy extrañas,

se iluminan a la luz de la noche

-las cosas vuelven a ser como lo que son, y uno mismo llega a ser como lo que es. (20)

La noche ocupa el lugar de la sacralidad en el trayecto de la voz. Los dones que posee sólo pueden asirse por intermedio de la aceptación de lo ambiguo como condición de diálogo trascendental. Estos dones circularán directamente desde lo sagrado hacia el cuerpo, encarnando una forma de conocimiento que constata la finitud tras la aceptación de la muerte. Aprendizaje éste que es el recurso fundamental de la relación de la voz con la noche y que actuará como una fuerza constante durante todo el ciclo ritual: ${ }^{5}$ "la gran intercesora, el abismo húmedo de vida primordial donde lo sagrado y lo profano confunden sus contornos, (donde) todo es nuevo como en el momento auroral" (Azcuy 1982, 89). Lo nuevo significa aquí el resultado de una operación de descentramiento del conjunto simbólico y de desplazamiento desde la superficie hacia la noche.

\footnotetext{
5 Conocer la verdad implica, bajo esta perspectiva, aprender de la muerte. "Saenz empleará el "morirse" como una revelación y una introducción a la vida nueva, inscribiéndose así en la simbología de la muerte y la resurrección. En este proceso que, partiendo del tú, será el tránsito a la vida nueva" (Wiethüchter 326). En la mirada del poeta morir es adquirir elementos que no estaban presentes en la vida o que habrían sido atrofiados. Su intención no está centrada en revertir los efectos de ese atrofiamiento sino en proponer una alteridad en la que ese daño no exista, pues habría sido superado por la propia visión que el ser humano hace de su vida. Lo poético es una vía para acercarse a este tipo de verdad.
} 
Lo primero será adentrarse en la espesura de la noche para siempre jamás.

Si destruyen la noche, ya no te importa:

el espacio de la noche que tú ocupas, seguirá siendo la noche: será tu noche, en un espacio indestructible. (24)

En este marco todas las nociones significantes que enlazan al día y su dinámica con la realidad entrarán en crisis. Aquello en lo que se presuma una utilidad para comunicar a favor de la superficie será borrado por la noche. Borradura ésta que opera en dos niveles. ${ }^{6}$ Por un lado, a través de una crítica constante a la idea de acumulación y de conflicto que representa poseer en las dimensiones de ser, de estar, y de conocer:

En realidad, me refiero al aprendizaje del conocimiento;

pues una cosa es cierta: no se puede conocer sin antes haber aprendido a conocer. (25)

Así se opone a lo visible, a lo contable, a lo que en la superficie representa material para el progreso mediante una realidad diferencial que lo mira como obstáculo a superar de cara a la "purificación de los sentidos y sensibilidades que embarazan el camino místico" (Molinos 1974, 94). Borrar implica, en este nivel, reconstruir el paradigma del aprendizaje como un ejercicio de vaciamiento: el individuo está más dipuesto a conocer en la medida en que menos cercado se encuentra por lo material.

Y, por otro lado, la borradura opera sobre el lenguaje poético al construir una separación efectiva entre el día y la noche como dos registros lingüísticos diferentes. La luz, el deber, las aspiraciones, las normas, constituyen una región explorada por formas linguísticas cuyo significado está directamente

\footnotetext{
${ }^{6}$ Lo pagano y lo sagrado son estados diferenciales en el proceso ritual. Sus puntos de encuentro son, también, como observaba Van Gennep, puntos de interacción entre estos estados: lo conflictivo aparece como una vía de negociación de prevalencia que, por un lado, busca imponer los elementos paganos para ser limpiados por la fuerza sagrada $y$, por otro lado, busca desplazar la naturaleza pagana a favor de una predominancia de lo sagrado. Hay, en ese contexto, una labor de borradura de los límites y sentidos de cada uno de estos estados, a favor de la composición liminal del territorio de su encuentro. La borradura funciona como una acción de deshacimiento de elementos propios de los estados paganos y sagrados, hacia un devenir heterogéneo en un tercero diferencial.
} 
relacionado con los actos cotidianos que, para Saenz, son superficiales. El signo y su significado son dispuestos en una cercanía tal que el lugar que podría ser ocupado por la metáfora se ve reducido constantemente. La palabra es cercada por los actos domesticados, por la la funcionalidad de la comunicación. La red del lenguaje, en el lado del día, ha atrapado todo:

Sencillamente, resulta sorpredente que hasta el momento la noche no haya sido eliminada de la faz del planeta:

liquidada y abolida para siempre, en aras del progreso de la humanidad y para mayor gloria de la tecnología: fantasía,

en procura de soluciones radicales para extirpar el mito de la

así como también para que la gente trabaje más y no duerma tanto. (23-24)

La noche, el olvido de sí mismo, la ruptura con el amor propio, por el contrario, abren otra región a partir del distanciamiento del signo y su significado, mediante la inclusión de estructuras que intentan cortar el sentido automático de lo comunicativo. Lo metafórico aquí gana densidad y logra la apertura de funciones adscritas sobre todo a lo contemplativo: las reiteraciones lingüísticas escritas como disposiciones al trance intentan detener los sentidos y ampliar así la dirección múltiple de cada uno de los posibles significados.

Pues la noche solo se da en la realidad verdadera, y no todos la perciben.

Es un relámpago providencial que te sacude, y que, en instante preciso, te señala un espacio en el mundo:

un espacio, uno solo:

para habitar, para estar, para morir $-\mathrm{y}$ tal es el espacio de tu cuerpo. (57)

Miguel Casado (2019) sostiene que la escritura poética tiene relación con el momento de pausa de los códigos lingüísticos porque crea un espacio de corte con el uso significativo de los términos. En La Noche esta pausa permite que la voz del poeta supere el cerco semántico que ordena, clasifica, juzga, jerarquiza; e ingrese a un espacio de significación en tránsito a través de un lenguaje que se desdobla y desborda los sentidos de comprensión posibles: 
Y si uno pregunta para qué aprender a morir, la respuesta surge de por sí:

aprender a morir es aprender a vivir.

Y aprender a vivir es, en definitiva, aprender a conocer;

pues no deberá olvidarse qué, para conocer, primero habrá que aprender a conocer. (39)

Saenz muestra una región donde la vida es deshecha constantemente por el conocimiento que habita en su anulación: la muerte. La noche, marginada por el día, se revela hasta invertir el sentido de la luz; y el conocimiento, que viene desde la borradura de la vida, coloca un nuevo orden en la realidad.

La palabra sobre la que ese nuevo orden se afirma está barrida de toda llenura cotidiana porque, al nacer de la oscuridad, ésta ha modificado sus relaciones con el significado debido a la serie de oposiciones entre vida/muerte, superficie/profundidad, día/noche. Configura un espacio para contemplar ese régimen desconocido que crece del otro lado de la noche y que, de a poco, fagocita la realidad superficial, vaciando el lugar que ésta ocupaba e inaugurándolo como un espacio para la nada, la nada germinal, como sugiere Wiethüchter: "[c]uando no hay nada que no puede ser negado, es la nada la que se afirma, es decir, la nada como cuerpo, como presencia en la vida de Saenz" (327). La nada constituye entonces el elemento estructural sobre el que la visión, el estado del ser y el lenguaje, por un lado, se distancian de las referencias cerradas a las funciones fisiológicas, sicológicas o lingüísticas solamente; $y$, por otro, amplían las formas de percepción con que el individuo absorbe la experiencia por fuera del marco paradigmático de la razón occidental. Espacio en desplazamiento sobre el que se asienta el proceso ritual.

\section{Tripartición: el desplazamiento ritual}

En el análisis de Rodrigo Díaz Cruz (1998) sobre la teoría ritual, la condición cíclica del rito se sostiene en su estructura compuesta por las secciones separación, liminalidad y agregación. En la separación, el individuo se aparta sistemáticamente del mundo de afuera para incorporarse a un estado de apertura frente a fuerzas externas convocadas al proceso. La liminalidad, núcleo del rito, es el punto de encuentro del individuo con esas fuerzas. Se trata de una relación de alteración radical que lo obliga a salir de sí mismo - una experiencia del éxtasis - para integrarse a la condición despersonalizadora que 
asimila lo proveniente de la fuerza convocada, en un proceso de crisis que incluye, en su punto más crítico, poner en juego la vida y la muerte. ${ }^{7}$ La agregación es la reintegración con la unidad original posterior a la interacción del individuo y las fuerzas convocadas; y es también el final del ciclo en el que la realidad se modifica a partir del desplazamiento del yo hacia la otredad. ${ }^{8}$ Pero este punto de modificación es, una vez más, el inicio de un nuevo ciclo ritual, secuencial en su reiteración hacia la renovación. El paso entre cada una de estas secciones está intercedido por lo que defino como puntos de modulación, lugares de intersección entre una etapa y otra que posibilitan intercambios simbólicos que amplifican o disminuyen el comportamiento de los elementos involucrados en el proceso ritual.

Van Gennep (2013) analizó este conjunto de etapas como un espacio para la crisis de formas sociales imperantes ya que el rito contendría una estructura opuesta a la norma social. Bajo este ángulo el rito se convierte en un espacio antiestructural en claro enfrentamiento con la superficie y la cotidianidad. En La Noche este nivel antiestructural está en diálogo con la experiencia poética. Las diferentes secciones del poemario muestran la modificación de los valores simbólicos de elementos como el día, la noche, la vida, la muerte, el silencio, la trascendencia, el aprendizaje, el olvido. Lo antiestructural aquí implica cuestionar su función automatizada y, sobre todo, movilizarlos hacia el cumplimiento de tareas de conocimiento propio, un aprendizaje hecho a partir de la perspectiva de la fugacidad y de la renovación ya que, al igual que en el proceso ritual, la agregación es solo una zona de tránsito hacia una nueva separación y experiencia liminal.

\footnotetext{
${ }^{7}$ Ariel Pérez (2011) resalta el desdoblamiento inidividual como una característica dentro de la poesía de Saenz. Esta idea muestra una acción voluntaria a la que sigue un tipo de conocimiento adquirido fuera del individuo y en desborde constante. Saenz se desplaza y abre zonas de conocimiento que parecen ver en la palabra una forma de modulación para ser enunciadas. Nestor Perlongher (2004) miraba estas zonas de modulación como un componente esencial del estado de éxtasis, pues por un intermediario efectivo que anticipe el encuentro con la realidad descentrada en el estado liminal, el mediador funciona hacia la apertura extrema, donde el nivel significante referencial del símbolo lingüístico es permeado por una heterogeneidad de significados. La plurisignificación de la palabra poética es una característica clave en el estado de éxtasis para permitirse diálogo y disputa desde el lenguaje escrito con el cambio que se opera en el individuo.

${ }^{8}$ La otredad en La Noche está propuesta sobre la idea de transformación que el individuo que se somete al proceso ritual logra una vez que se ha desplazado entre sus diferentes etapas. Su base es la noción de un devenir otro, en franco diálogo con un ciclo en el que se renueva periódicamente.
} 


\section{Separación}

Para ingresar a ese aprendizaje es necesaria la voluntad de separarse, que "[s]eguramente requiere mucha humildad y mucho gobierno" (39), tras una serie de actos que permiten la purificación de un estado que la superficie ha ido atrofiando. Saenz relata estos actos en la primera sección del poemario, titulada "La Noche". Meditación y contemplación aparecen como actividades centrales que incrementan su grado de radicalidad en tanto separan al individuo de la superficie del día y lo integran a la claridad de la noche. Son, en su extremo, una purga a través de la que el orden armónico del espíritu, extraviado en el atrofiamiento funcional, es convocado de nuevo. A ese dolor el individuo se entrega con voluntad, paciencia y calma. Una entrega que, además, implica estar abierto al intercambio de dones con la noche, fuerza externa convocada para este tránsito. Esta apertura es el punto de intersección con la mirada mística que Saenz explora a profundidad y que permite, en este nivel, la división clara entre lo pagano y lo sagrado para reconfigurar el lugar donde el individuo dispondrá su recogimiento. En esta reconfiguración hay un quiebre inicial: la relación superficial que asocia la realidad con el progreso es cuestionada. Afuera acontece la acumulación material-verbal que causa una sistemática automatización del ser humano frente a la idea del avance, de la superación. La tecnología, por ejemplo, gana autoridad en tanto mayor claridad riega sobre las zonas que permanecían en el misterio de la oscuridad; su jerarquía se intensifica más y mejor por su eficacia ante lo desconocido. Eso se traduce en el uso de la palabra funcionalizada hacia un fin concreto en el que mientras menos se repitan las cosas y más ordenados estén los significados, mayor eficacia se posee ante la realidad:

Capaz que en una de esas le inyecten a la noche unas cápsulas de láser y le endosen quien sabe qué artefactos de cobalto, para que cumpla una función verdaderamente útil. (24)

Saénz opone a estos atributos superficiales lo que denomino una actitud contra-acumulativa que enrarece la eficacia comunicacional y tecnológica para mostrar un camino alterno. No acumular implica practicarse para conocerse. Distorcionar la línea histórica de progreso frente al ciclo en el que el individuo plasma su recogimiento. De la mano de esa actitud se construye la tarea del iniciado. Como todo proceso místico, el individuo que inicia este camino busca superarse a sí mismo tras la necesidad de conocer. Este conocimiento se 
desprende del estado de trance aperturado por el ciclo en el que ingresa el individuo y que obliga a pausar la conciencia crítica desorientando a lo racional:

Nadie puede pasar al otro lado de la noche:

el otro lado de la noche es una región prohibida, y solo podrán entrar en ella los sentenciados. (15)

Lo iniciático, resaltado con insistencia por Saenz en esta sección, es sobre todo una metodología que pone en crisis la versión unitaria de la realidad y desarma ese vínculo que la unía a la idea de progreso. Propone en su lugar una nueva forma relacional: cualquier cosa que sea la identidad, en las etapas de desplazamiento, en los segmentos rituales, afectará a cualquier cosa que sea la realidad. La crisis y la modificación son el centro de esta equivalencia con la que Saenz propone una acción contracultural que distancia al individuo de la multitud que la cultura ha domesticado, colocándolo en acción directa con fuerzas que lo sobrepasan y están ahí para ser conocidas de una manera diferente.

En La Noche esa acción contracultural inicia con la ingesta de alcohol, que es el ingreso a la práctica de una actitud de disconformidad con el yo cultural. La figura del aparapita, personaje tutelar en el universo de Saenz, materializa esta disconformidad: tras el reiterado consumo de alcohol, el indígena de la altura deviene en un ser separado de la superficie e integrado en una tarea crucial de contemplación. ${ }^{9}$ Vapuleado, segregado, marginado en la superficie, el aparapita modifica sus ejes de referencia al interior del conocimiento explorado por Saenz en el que todos los sufrimientos o pesos simbólicos aledaños a su figura se muestran como estados de un conocimiento distinto. $\mathrm{Si}$ "desordenar el cuerpo vía delirio o alcohol es un pasaje necesario para construirse como sujeto" (Velásquez Guzmán 2011, 11), si la ausencia de sentido adelanta a la acción, las expectativas de enunciación de todo acto o palabra se reducen, dejando a los actos o palabras en sí mismos:

Estos bebedores han aprendido muchas cosas y tienen mucha paciencia,

\footnotetext{
${ }^{9}$ Saanz ubica a la figura del aparapita bajo las características de un hombre, de raíz étnica Aymara, que intentando dejar atrás la pobreza de su lugar de origen ha migrado a los centros urbanos donde ejerce labores de carga principalmente en los mercados de abasto. Su ubicación social en los lugares de destino lo liga a la pobreza media y extrema, y bajo condiciones de riesgo para la salud y la supervivencia.
} 
y saben que el otro lado de la noche se halla en el interior de sus espaldas,

y que se halla asimismo en sus gargueros,

los cuales conservan siempre un resabio de alcohol,

lo que precisamente tiene la virtud de atormentarlos sin cesar, durante el largo, largo tiempo que dura la noche en el otro lado de la noche. (14)

El punto más alto de esta acción es también el punto donde el desarraigo es total. Miguel de Molinos observó en este desarraigo la dimensión de la profundidad que ha tenido la tarea del iniciado. Si ha sido fructífera habrá distanciado a su ser del amor propio: "[n]egarse a sí mismo en todas las cosas, estar sujeto al parecer ajeno, mortificar continuamente todas las pasiones interiores, aniquilarse en todo y por todo, así mismo, seguir siempre lo que es contrario a la propia voluntad, al apetito y juicio propio, es de pocos" (193). Esa distancia con el amor propio es, bajo la propuesta de Saenz, la desocupación de cualquier forma de expectativa consigo mismo: no esperar nada, no acumular nada. Ocupar el tiempo y el espacio de un modo distinto, una forma de elevación espiritual hacia el éxtasis que deviene de la negación a cualquier significación cotidiana.

\section{El momento liminal}

La elevación espiritual es el lugar de tránsito hacia el espacio liminal. Van Geneep definió lo liminal como una "antiestructura social ambigua" (25), en la que la transformación sucede a propósito del conflicto entre las distintas fuerzas, no domesticadas, que pugnan por imponerse entre sí. Victor Turner (1988) sugirió que un conflicto de esta naturaleza puede desatarse porque los elementos que ingresan al estado liminal están conformando un modelo de interacción en el que "en cuanto seres liminales que son no tienen status" (102). Jaime Saenz muestra lo liminal como un estado de emancipación de la voz que, en lo superficial, es habitada por una serie de condiciones jerárquicas. Distanciado de esas jerarquías hay un nuevo espacio para decir sin tener necesariamente que comunicar o responder a un tipo de naturaleza humana o animal que condicione la enunciación. Ese decir, es amplio porque engloba diferentes registros, desde lo mítico hasta lo moderno, logrando que exista el desplazamiento de una serie de fragmentos sonoros, visuales, performánticos desplegados durante la transformación. 
En la segunda sección del poemario, "El Guardian", Saenz relata el encuentro con la liminalidad. Se trata de un momento de disociación entre cuerpo y espíritu. El poeta presenta al cuerpo recostado, observado por otro cuerpo, expulsado de su interior para relatar diferentes estados de abandono y desposesión:

Este pobre cuerpo, abandonado;

este pobre cuerpo, ido y botado, y bastante olvidado, con una presencia que solo se deja presentir por pesantez,

y con patas como palos aquí, y con brazos ardientes y paralizados allá (37)

En la novela Felipe Delgado (1979), Saenz rodea una noción que aquí viene al caso: "[m]uy grande es, y muy grave, la desproporción del vivir y la vida; por eso se llama esperanza. Sin embargo es posible volverse vida; sacudirse este hechizo del vivir, sacarse el cuerpo. Tal la esperanza sin esperanza" (22). Y es que en "El Guardian", Saenz se saca el cuerpo. Borra el afuera a través de la separación que muta su palabra al acto contemplativo. Así proyecta a su doble, surgido de la purga, y en dirección hacia un nuevo tipo de distanciamiento pues,

La posibilidad de disociarlo (al doble) del cuerpo físico mediante actos voluntarios, fue uno de los secretos mayores de los antiguos sacerdotes y formó parte de los antiguos misterios. Los iniciados se hacían acreedores a ese nombre cuando por medio de una rigurosa preparación psicofísica lograban desprenderse del cuerpo y proyectarlo conscientemente más allá del espacio y el tiempo. (Azcuy 106. El paréntesis es mío).

Con esta apertura el poeta se entrega al éxtasis. Santo Tomás de Aquino vio en esta entrega un vaciamiento de forma y significado a ser llenados, posteriormente, con "la plenitud de lo que no tiene forma ni imagen y encierra a la vez la potencialidad infinita de todas las formas de la creación" (Valente 16). El cuerpo es el lugar de vaciamiento y llenura para intentar otro modo de ser: ser a través de dejar de ser. Parar la máquina de ser implica, para Saenz, habitar un estar dentro del cuerpo en tránsito y reiteración.

Poseer será una idea que en el pensamiento de Saenz estará fuertemente cuestionada pues no refiere solamente a la materia que crea dependencia en el individuo y que, como el caso de la tecnología, pone luz donde la oscuridad es un lenguaje de trascendencia, sino que apunta sobre todo a la escisión que 
el cuerpo tiene con el espíritu. Rasgo clave que caracteriza la tercera sección del poemario, "Intermedio", donde el delirio apocalíptico de quien narra apunta precisamente al cuerpo.

\section{$[\ldots]$}

Por lo demás, existían famosos al par que despiadados tecnólogos entre los negros;

y su único oficio era destruir y matar. (52)

Las lecturas místicas de Saenz representan un firme rechazo a toda forma de posesión que signifique la negación del vínculo espiritual. Lo que está fuera del ser, lo que mira al cuerpo fuera del cuerpo, es un estado de transición en el que los sentidos de absorción de la realidad están siendo radicalmente cuestionados. La desposesión que ha iniciado al sacarse el cuerpo se extenderá hacia la redefinición de las relaciones que el individuo tiene con la realidad para refundar las relaciones que tiene consigo mismo. En este nivel se puede observar, por ejemplo, que en la figura donde la muchedumbre mira a un alcohólico, Saenz ve a alguien que ha rehecho sus vínculos con la vida y que ha logrado una forma de ingresar en ella que no es común y que es apertura a la búsqueda espiritual. ${ }^{10}$

El otro lado de la noche es una nueva naturaleza propagada sobre el camino de desposesión que gana radicalidad a medida que la transformación opera en el individuo. Allí, el poeta cumple la máxima de San Juan de la Cruz: "para venir a lo que no posees, has de ir por donde no posees" (Valente 17). El cuerpo, en el espacio liminal, está suspendido. Las sensaciones que lo rodean no alcanzan a ser agarradas por las palabras. No las conocemos, están enterradas dentro de eso que aparenta ser el cuerpo, en otro cuerpo que cuestiona eso que siente y se pregunta si en realidad lo siente. Un cuerpo nuevo que se asoma a la versión más vital de la muerte. Por eso lo revolucionario aquí es el lenguaje. Saenz explota el centro de condensación del significado y se opone a la autoridad mecanizadora de la sensación,

\footnotetext{
10 La referencia popular asocia al aparapita con el consumo excesivo de alcohol, adjudicándole una serie de antivalores opuestos a la noción de progreso que, como proponemos, Saenz critica. La propia figura del poeta, a lo largo de distintas lecturas, ha sido colocada en el margen del artista bohemio, perdido en los sentidos desbordados del alcohol, algo que contrasta con la visión de conocimiento y experiencia que él explora en este poemario.
} 
llevándose a sí mismo a un estado de vaciamiento de los sentidos, abiertos ahora a las fuerzas de la noche. Lo que resulta es una entidad tercera: ni Saenz ni la noche han pasado la frontera del estado liminal. La borradura ha actuado sobre ellos, sobre sus cualidades, para devenir en otro tiempo y espacio integrados en una dialéctica que no conoce más la superficie y que actúa de forma inaugural en conjugación con la unidad original. El reencuentro se ha cumplido.

\section{Agregación}

En la sección final del poemario, "La Noche", se completa el proceso de agregación a través de dos vértices definidos: las evidencias que ha dejado el lenguaje durante su transformación y la tensión identitaria del visionario. El lenguaje está orientado a un estado de contemplación en el que la negación de toda conquista es ahora el lugar desde el que se afirma la vida:

¿Qué es la noche? - uno se pregunta hoy y siempre.

La noche es una revelación no revelada. (62)

El axis mundi, el centro del individuo, es en este sentido una actividad que no tendrá fruto y que solo existe en su práctica presente. Este desplazamiento sucede durante el lenguaje de transformación. Resalto el durante pues se trata de un lugar del acontecimiento que es continuamente generado en la medida en que el sujeto se encuentra en una práctica contemplativa. La visión de Saenz implica ocupar el espacio de la nada. Allí es donde el lenguaje acontece, donde el individuo encarna eso que será borrado adelante. Esa nada tan temida por el hombre de la superficie y sus ocupaciones es el territorio donde brota el otro lado de la noche.

Montserrat Fernández vio en ese espacio un "lugar in-trabajado" (2011, 26) y fértil para un pre-lenguaje, articulado por los hallazgos que el individuo ha tenido en su proceso de internación en el campo ritual: una entidad en materialización precaria, en dirección hacia un momento de maduración opuesta a la idea de continuidad, pues al regresar o asumir el punto de partida desde lo incompleto, desafía la llenura de la superficie, los deberes y las distracciones, y se concentra en oír la bulla de la nada. Saenz cierra este ciclo con una revelación: lo que ha hecho la entidad resultante de la agregación ha sido afectar dimensionalmente la identidad del individuo, convirtiéndola en un elemento para la alteración. La relación con la realidad es heterogéna, ahí 
donde la identidad elije decir, la realidad responde de modo radicalmente diferente y su réplica significa el antecedente para ingresar, una vez más, en el ciclo ritual de La Noche.

La tarea del visionario deviene de esa relación identidad-realidad. En este poemario, la escritura consiste en el desborde radical de la mismidad para devenir en otredad. "Entenderse con 'el otro', con 'lo otro', implica la tarea de ir más allá de sí mismo: volverse diferente de lo que era” (Echeverría 1998, 25). La manera ambivalente con la que se habita es la esencia de la identidad de agregación. Siempre habrá otro, con el que se convive, deseable y aborrecible a la vez, al que solo se puede aceptar en la medida en que el yo se modifica de forma constante y esencial. Pero esta aceptación no es pasiva; implica un enfrentamiento constante, un acto de "codigofagia" (Echeverría 31), un desplazamiento constante de los elementos que definen la identidad en la medida en que los pesos de su significación son distorsionados continuamente. La noche devora sin freno el centro de la simbolización del día, del deber, de la norma, hasta destruirlos y esparcir sus ruinas sobre un individuo que las encarna.

Esta visión es la reintegración al ciclo ritual por fuera de cualquier posibilidad de inicio o retorno. En la entidad devenida se guarda el impulso de la borradura, de la no obtención de nada a riesgo de interrumpir lo verdaderamente útil: practicarse para aprenderse.

\section{Conclusión}

El acercamiento entre La Noche y el proceso ritual muestra cómo, a partir de la modificación de los paradigmas sensoriales y simbólicos del día y la noche, Saenz ingresa a un camino de transformación personal en el que lo identitario es escenario de una crisis continua a favor del camino místico de devenir otro.

El cumplimiento de una serie de pasos iniciáticos para lograr esa revelación, a partir de una concepción distinta de tiempo y espacio, guía la voz poética hacia una serie de alteraciones que reconfiguran el lugar de su enunciación así como las formas lingüísticas escritas mediante las que Saenz explora el cambio. Los principios místicos a los que el poeta atiende son fundamentales en este proceso. La escisión del mundo, el deshacimiento personal, el ingreso a un proceso contemplativo por intermedio de la desposesión y la ingesta del alcohol son características que singularizan la interacción con las versiones de la realidad y que permiten, por otro lado, el acercamiento entre la escritura y el proceso ritual. Resalto, en este sentido, el 
diálogo entre las secciones de La Noche y el rito, en el que se encuentran puntos de intersección a partir del proceso de borradura y ocupación del vacío, la acción del espacio liminal en la reconfiguración del lugar ocupado por el cuerpo y la versión del retorno a una realidad modificada.

El poeta acepta su naturaleza finita y radicaliza el núcleo de conocimiento al reemplazar el lugar referencial que ocupa la vida por la muerte. La concepción del cuerpo en Saenz es la evidencia de este proceso: un cuerpo que está muriendo a cada instante es un camino a la revelación. Un cuerpo abierto. Un cuerpo que se hace en transformación.

\section{Bibliografía citada}

AZCUY, Eduardo. 1982. El ocultismo y la creación poética. Caracas: Monte Ávila Editores.

BORGES, Jorge Luis. 1960. El Hacedor. Buenos Aires: Emecé Editores.

CASADO, Miguel. 2019. Un discurso republicano. Ensayos sobre poesía. Madrid: Libros de la Resistencia.

DÍAZ CRUZ, Rodrigo. 1998. Archipiélago de rituales: Teorías antropológicas del ritual. Barcelona: Anthropos. I

DOUGLAS, Mary. 2001. Purity and Danger. An Analysis of Concepts of Pollution and Taboo. New York: Routledge.

ECHEVERRÍA, Bolívar. 1998. La modernidad de lo barroco. Ciudad de México: Editorial Era.

FERNÁNDEZ MURILLO, Montserrat. 2011. "La noche: El horror vacui en la poética de Jaime Saenz". La crítica y el poeta. Jaime Saenz. Montserrat Fernández Murillo et. al., coords. La Paz: Plural Editores. 23-60.

MOLINOS, Miguel de. 1974. Guía Espiritual seguida de la defensa de la contemplación. Barcelona: Barral Editores.

PÉREZ, Ariel. 2011. "Más allá del más allá de todos los caminos". La crítica y el poeta. Jaime Saenz. Montserrat Fernández Murillo et. al., cords. La Paz: Plural Editores. 173-190.

PERLONGHER, Néstor. 2004. Papeles Insumisos. Adrián Cangi y Reynaldo Jiménez, eds. Buenos Aires: Santiago Arcos.

SAENZ, Jaime. 1984. La Noche. La Paz: Talleres Escuela de Artes Gráficas Del Colegio Don Bosco.

---. $\quad$ 1979. Felipe Delgado. La Paz: Difusión Ltda.

SEVERI, Carlo. 2006. "Language". Theorizing Ritual. Vol. 1. Issues, Topics, Approaches, Concepts. 114 (1): 583-593.

TURNER WITTER, Victor. 1988. El proceso ritual: estructura y antiestructura. Versión castellana de la editorial, revisada por Beatriz García Ríos. Madrid: Taurus. 
VALENTE, José Ángel. 1974. Ensayo sobre Miguel de Molinos / Miguel de Molinos. Guía espiritual seguida de la Defensa de la contemplación. Barcelona: Barral Editores.

VAN GENNEP, Arnold. 2013. Los ritos de paso. Juan Ramón Aranzadi, trad. Madrid: Alianza Editorial.

VELÁSQUEZ GUZMÁN, Mónica. 2011. "Palabras Preliminares”. La crítica y el poeta. Jaime Saenz. Montserrat Fernández Murillo et. al., coords. La Paz: Plural Editores. 7-22.

WIETHÜCHTER, Blanca. 1975. "Estructuras de lo imaginario en la obra poética de Jaime Saenz". En Jaime Saenz, Obra Poética. La Paz: Biblioteca del Sesquicentenario de la República. 267-425. Program, and is cosponsored by the University of Pittsburgh Press. 